Dr Slobodan Bursać, general-major, dipl. inž. Vojnotehnicka akademija VJ,

Beograd

\section{TERMALNI ODRAZ LETELICE}

UDC: $543.57: 772.96: 623.746$

Rezime:

Termalni odraz letelice modeliran je pomoću izračunavanja iradijanse na mestu posmatrača (detektora) od elementarnih površina letelice. Elementarna površina letelice je trougao, koji je opisan temperaturama temena $i$ kosinusom ugla između normale površine $u$ težištu trougla, $i$ pravca ka detektoru. Vidljivost, odnosno, zaklonjenost (preklapanje) elementarnih površina kontrolisane su pomoću perspektivne transformacije objekta u ravan. Matematicki model termalnog odraza letelice ukljucuje $i$ uticaj atmosfere preko Programskog paketa LOWTRAN.

Ključne reči: termalni odraz, infracrveni odraz, termalna slika letelice.

\title{
AIRCRAFT THERMAL SIGNATURE
}

\section{Summary:}

Aircraft thermal signature has been modelled by calculating irradiance at ihe observer's spot (detector position) from aircraft elementary surfaces. The elementary surface is a triangle determined by its corner temperatures and the cosine of the angle between the normal surface in the angle centre of gravity and the detector direction. Visibility and overlapping of elementary surfaces are controlled using the perspective transformation of an object into the plane. The mathematical model of aircraft thermal signature also includes the atmosphere influence through the LOWTRAN software.

Key words: Thermal signature, infrared signature, thermal image of aircraft.

\section{Uvod}

Savremena borbena dejstva, vođena poslednjih desetak godina u Iraku, Bosni i SRJ, ukazuju na sve veću upotrebu pasivnih optoelektronskih senzora. Posebno mesto u navigaciji, izviđanju, vođenju i samonavođenju raketa i bombi, kao i u protivvazdušnoj odbrani, zauzima termovizija.

Pod termovizijom se podrazumeva formiranje slike scene na osnovu njenog toplotnog infracrvenog zračenja. Poznato je da se slika scene $u$ vidljivom opsegu talasnih dužina $(0,4$ do $0,7 \mu \mathrm{m})$ formira na osnovu refleksije prirodnih ili veštačkih izvora svetlosti od objekata na sceni. Međutim, termovizija formira sliku na osnovu sopstvenog zračenja (emisije) objekta na sceni u infracrvenom području talasnih dužina (1 do $1000 \mu \mathrm{m})$, a najčešće u opsegu 3 do $5 \mu \mathrm{m}$ i 8 do $12 \mu \mathrm{m}$. Prema tome, fizički princip formiranja termalne infracrvene slike scene ne zahteva dodatne izvore zračenja, već detektuje i identifikuje zračenja objekata na sceni. 
Pored primene u privredi, termovizija je našla masovnu primenu i u vojsci. Koristi se u navigaciji letelica, navigacijsko-napadnim sistemima vazduhoplova, tenkova i brodova, vođenju i samonavođenju borbenih sredstava (raketa i bombi) i u sistemima protivvazdušne odbrane.

$U$ radu je analiziran termalni odraz letelica $\mathrm{u}$ funkciji potpuno pasivnog sistema protivvazdušne odbrane. Termovizija omogućava osmatranje vazdušnog prostora, detekciju, identifikaciju i praćenje letelica u uslovima savremenog bojišta (dan-noć, elektronsko ometanje radara i komunikacija). Radi toga je bilo potrebno modelovati termalni odraz letelica $\mathrm{i}$ analizirati mogućnost detekcije i identifikacije.

\section{Modelovanje termalnog odraza letelice}

\section{Izračunavanje spektralne iradijanse}

Da bi se odredio termalni odraz letelice potrebno je, najpre, njenu površinu izdeliti na elementarne površine. To je najlakše uraditi tako što se površina letelice definiše koordinatama određenih tačaka, kroz koje se može provući niz linija koje obrazuju mrežu oblika četvorougla.

Međutim, cetvorouglovi nisu pogodni za izračunavanje radijanse jer cetiri tačke, u opštem slučaju, ne moraju da leže u jednoj ravni. Da bi se obezbedila komplanarnost tačaka koje obrazuju elementarnu površinu, svaki od četvorouglova deli se dijagonalno na dva trougla. Zatim se odrede parametri ravni u kojoj leži trougao i kosinus ugla između te normale i pravca koji obrazuju težište trougla i položaj detektora. Spektralna iradijansa nekog trougla na mestu detektora dobija se iz izraza [1]:

$$
\begin{aligned}
& \Delta \mathrm{H}_{\lambda}=\Delta \mathrm{A}_{1} \cdot \frac{\cos \theta_{1}}{\mathrm{R}^{2}} \cdot \frac{\mathrm{C}_{1}}{\lambda^{5}} \cdot \\
& \frac{\varepsilon_{\lambda}}{\exp \left(\frac{3 \mathrm{C}_{2}}{\lambda\left(\mathrm{T}_{1}+\mathrm{T}_{2}+\mathrm{T}_{3}\right)}\right)-1}
\end{aligned}
$$

gde su $T_{1}, T_{2}$ i $T_{3}$ temperature pridružene temenima trougla. Ukupna spektralna iradijansa dobija se kao suma spektralnih iradijansi svih četvorouglova koji se vide iz tačke u kojoj se nalazi detektor.

\section{Perspektivna transformacija $i$ odredivanje vidljivosti elementarnih poligona}

Perspektivna transformacija zasniva se na određivanju tačaka prodora pravih, koje prolaze kroz tačke na površini trodimenzionog (3D) tela i oka posmatrača, $\mathrm{u}$ ravan perspektivne transformacije. $\mathrm{Ra}$ van perspektivne transformacije je ravan normalna na duž koja spaja oko posmatrača i koordinatni početak, a nalazi se na rastojanju $\mathrm{O}_{\mathrm{p}}$ od posmatrača.

Koordinatne ose perspektivnog koordinatnog sistema određene su na sledeći način [1]:

- $z_{p}$ osa se poklapa sa duži koja spaja koordinatni početak i oko posmatrača, a usmerena je ka oku posmatrača tako da se on nalazi na $z$ osi perspektivnog koordinatnog sistema;

- $x_{p}$ i $y_{p}$ ose određene su pravilom desnog triedra (slika 1).

Koordinate tačaka u perspektivnom koordinatnom sistemu $\left(\mathrm{x}_{\mathrm{p}}, \mathrm{y}_{\mathrm{p}}\right)$ služe za određivanje vidljivosti elementarnih poligona i zavise od rastojanja ravni perspektivne transformacije od posmatraca, od- 
nosno detektora. Ovo rastojanje može se birati proizvoljno, a u računarskom programu koji je razvijen može se menjati promenom parametra „ZOOM“ kako bi se mogla prikazati perspektivna transformacija celog objekta.

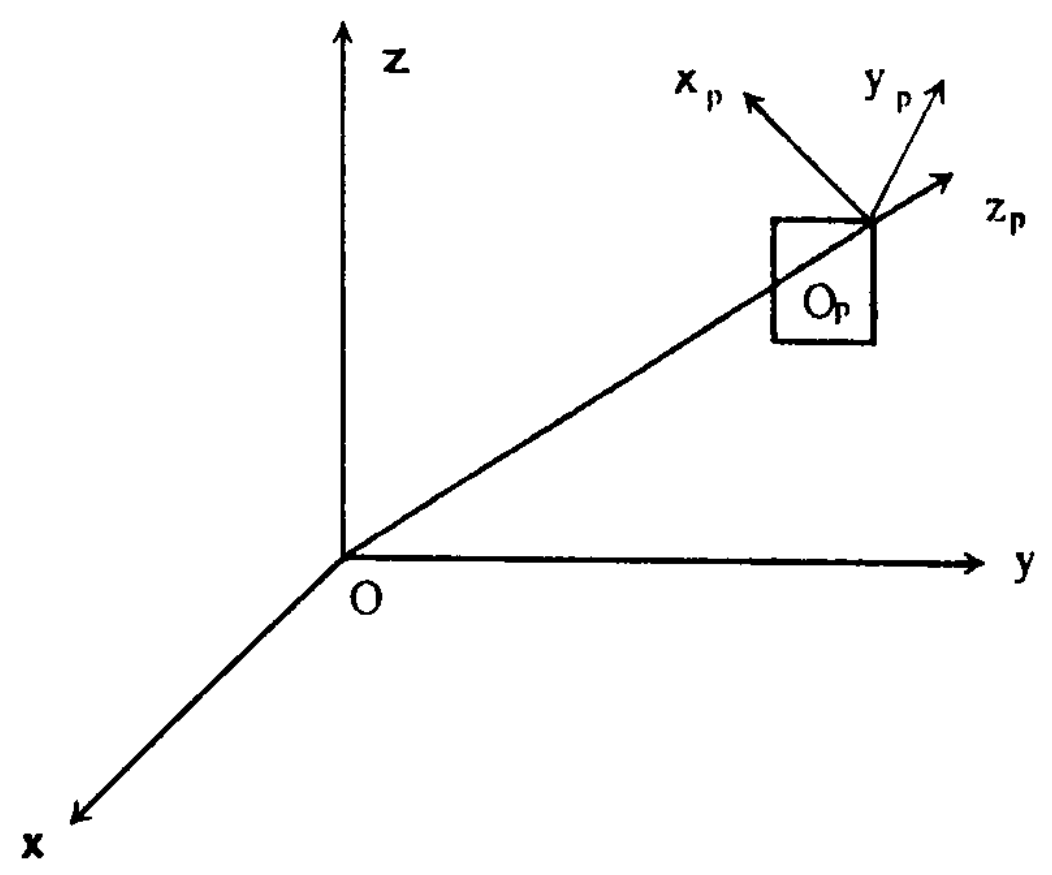

Sl. 1 - Koordinatne ose perspektivnog koordinatnog sistema
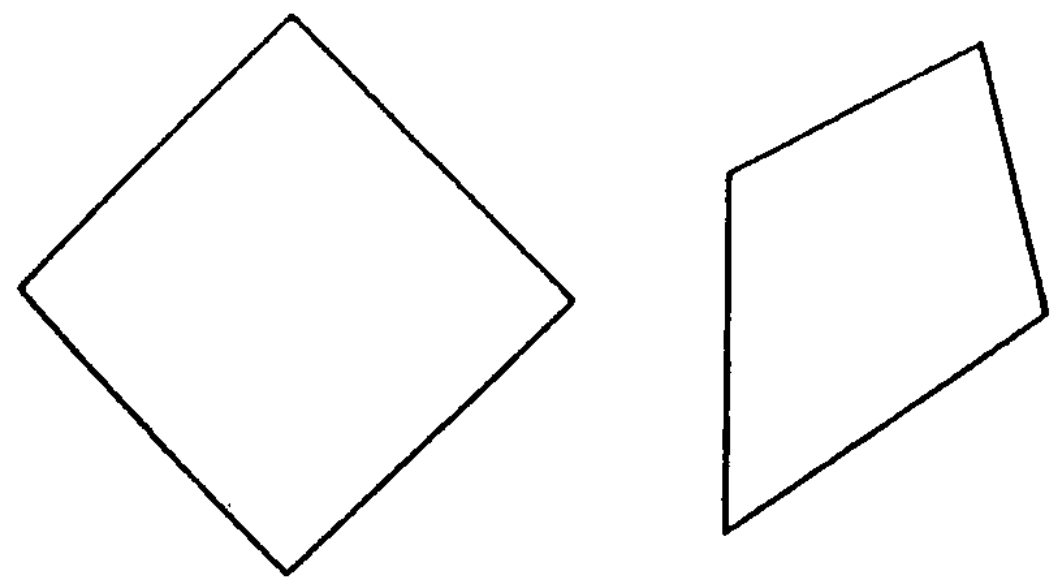

Sl. 2 - Upoređivanje zaklonjenosti poligona

Vidljivost poligona, koji se nalazi na površini 3D objekta, određuje se primenom postupka upoređivanja zaklonjenosti poligona (slika 2).

Postupak se odvija tako što se odrede perspektivne koordinate temena poligona u perspektivnoj ravni. Nakon toga utvrđuju se parametri duži koje spajaju susedna temena poligona, a zatim se ispituje da li se neke od duži dva poligona seku.
Postoji više mogućih slučajeva. Ako među dužima koje predstavljaju stranice dva poligona nema takve dve koje se seku, pri cemu je jedna stranica jednog poligona a druga stranica drugog poligona, tada se ova dva poligona međusobno ne zaklanjaju. To može da znači da se oba poligona vide ili da se ni jedan od njih ne vidi (ukoliko oba zaklanja neki treći poligon). Ovaj slučaj prikazan je na slici 2.

Ukoliko se pronađu duži koje se seku u ravni perspektivne transformacije, tada je jedan od poligona zaklonjen na $3 \mathrm{D}$ koordinate, a zatim se određuju parametri ravni u kojoj se nalazi jedan od poligona. Nakon toga pronađe se tačka na sredini stranice, koja pripada drugom poligonu, a za koju je utvrđeno da se u ravni perspektivne transformacije seče sa nekom od stranica drugog poligona. Zatim se odrede parametri prave koja prolazi kroz oko posmatrača i tu tačku, i nađe tačka prodora ove prave $u$ ravan $u$ kojoj se nalazi prvi poligon. Ukoliko je ova tačka bliža posmatraču od tačke na sredini jedne strane drugog poligona, tada se drugi poligon ne vidi, a prvi se vidi, i obrnuto. Ovaj slučaj prikazan je na slici 3.

Ukoliko se ne nađu dve duži koje se $\mathrm{u}$ ravni perspektivne transformacije seku, to još ne znači da se poligoni ne zaklanjaju.

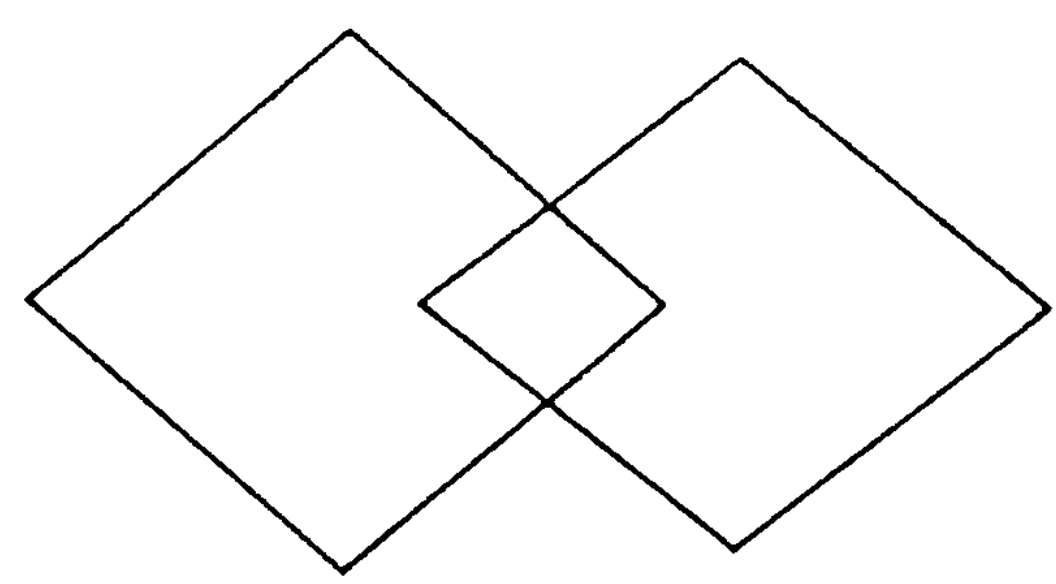

Sl. 3 - Upoređivanje zaklonjenosti poligona 
Moguće je da se jedan od poligona nalazi unutar drugog poligona, a sve to u ravni perspektivne transformacije. Tada se vidljivost određuje tako što se uzme bilo koja tačka koja pripada prvom poligonu (npr. jedno od temena ili tačaka na sredini jedne od stranica) i ista takva tačka koja pripada drugom poligonu. Zatim se odredi koja je od njih dve bliža posmatraču. Ako je to tačka koja pripada prvom poligonu, tada se on vidi, a drugi poligon se ne vidi, i obrnuto. Ovaj slučaj prikazan je na slici 4.

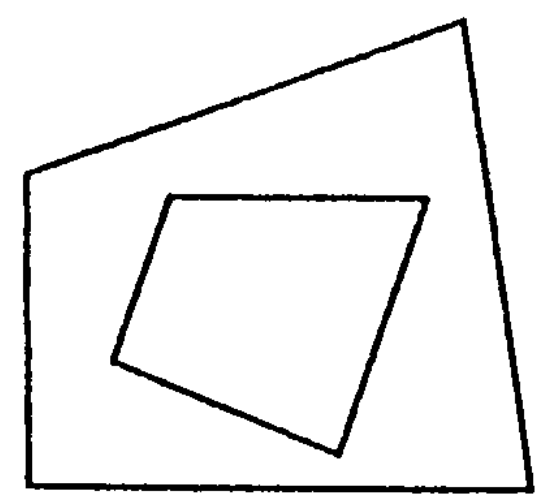

Sl. 4 - Upoređivanje zaklonjenosti poligona

Ceo postupak predstavlja kvadratni algoritam koji se realizuje u vidu petlje:

For $1:=1$ To $\operatorname{dim}$ Do

For $\mathrm{j}:=1$ To $\operatorname{dim}$ Do

Ovakvi algoritmi nisu pogodni za primenu, jer povećavanje dimenzija problema za n puta produžava vreme izvršavanja za $\mathrm{n}^{2}$ puta. Da bi se to izbeglo $\mathrm{u}$ postupku inicijalizacije izračunavaju se perspektivne koordinate svih temena poligona.

Zatim se za svaki poligon u ravni perspektivne transformacije odredi pravougaonik koji ga obuhvata (slika 5). Pravougaonik je definisan sa dva temena, (gore desno i dole levo), pri čemu su koordinate temena:
$A\left(X_{\max }, Y_{\max }\right) \quad$ i $\quad B\left(X_{\min }, Y_{\min }\right)$.

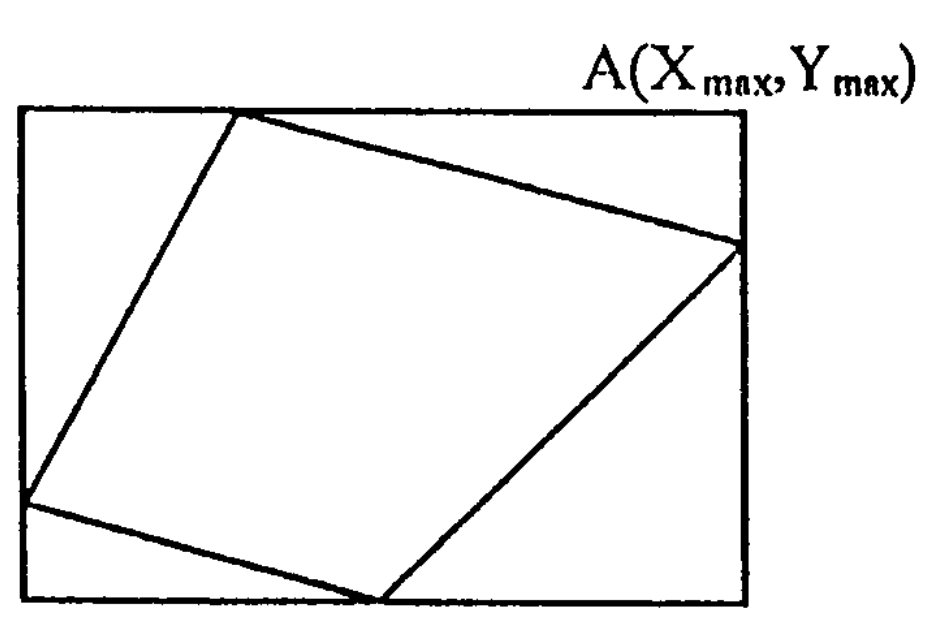

$\mathrm{B}\left(\mathrm{X}_{\min }, \mathrm{Y}_{\min }\right)$

Sl. 5 - Upoređivanje zaklonjenosti poligona

Ukoliko je poligon nepravilan četvorougao čija su temena: $A_{1}\left(X_{1}, Y_{1}\right)$, $A_{2}\left(X_{2}, Y_{2}\right), A_{3}\left(X_{3}, Y_{3}\right)$ i $A_{4}\left(X_{4}, Y_{4}\right)$, tada se temena $\mathrm{A}$ i $\mathrm{B}$ određuju na sledeći način:

$\mathrm{X}_{\max }=\max \left(\mathrm{X}_{1}, \mathrm{X}_{2}, \mathrm{X}_{3}, \mathrm{X}_{4}\right)$
$\mathrm{X}_{\min }=\min \left(\mathrm{X}_{1}, \mathrm{X}_{2}, \mathrm{X}_{3}, \mathrm{X}_{4}\right)$
$\mathrm{Y}_{\max }=\max \left(\mathrm{Y}_{1}, \mathrm{Y}_{2}, \mathrm{Y}_{3}, \mathrm{Y}_{4}\right)$
$\mathrm{Y}_{\min }=\min \left(\mathrm{Y}_{1}, \mathrm{Y}_{2}, \mathrm{Y}_{3}, \mathrm{Y}_{4}\right)$

Na taj način svaki poligon je opisan pravougaonikom koji određuje jedan deo ravni perspektivne transformacije. Pre nego što se krene u postupak određivanja vidljivosti dva poligona, najpre se proveri da li se njihovi pravougaonici, koji su određeni na pomenuti način, preklapaju u ravni perspektivne transformacije. Ako nema preklapanja tada se ni poligoni ne preklapaju, jer nisu u istom delu ravni perspektivne transformacije (slika 6).

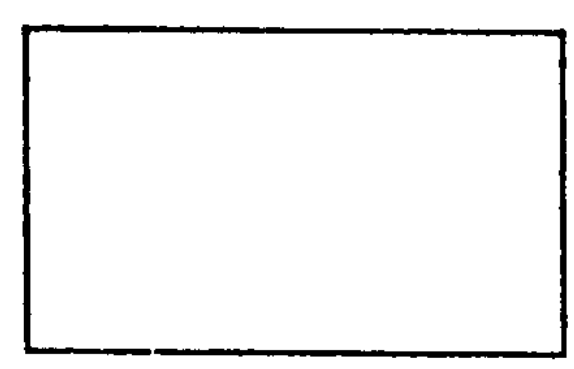

Sl. 6 - Uporedivanje zaklonjenosti poligona 
Ako se pravougaonici preklapaju poligoni se mogu preklapati (slika 7), ali i ne moraju (slika 8). Na taj način se za svaki poligon broj poligona za koje se sprovodi procedura, opisana na početku poglavlja, drastično smanjuje, a za ostale poligone se obavlja najobičnije upoređivanje realnih brojeva koji određuju temena pravougaonika.

Drugo ubrzanje postiže se tako što se iz unutrašnje FOR-petlje izlazi čim i-ti ili $j$-ti poligon promeni vidljivost (postane nevidljiv).

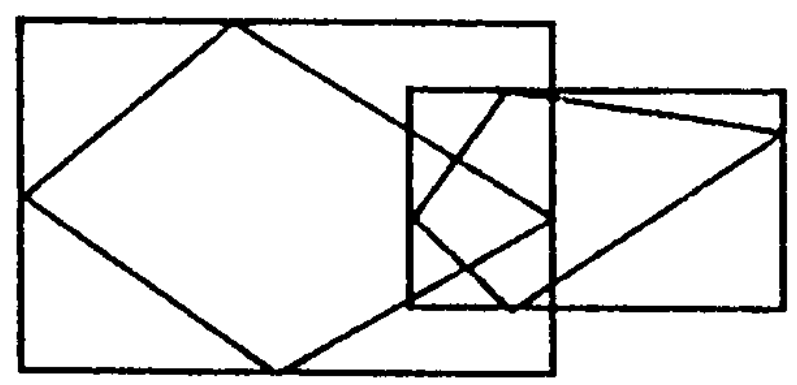

Sl. 7 - Upoređivanje zaklonjenosti poligona

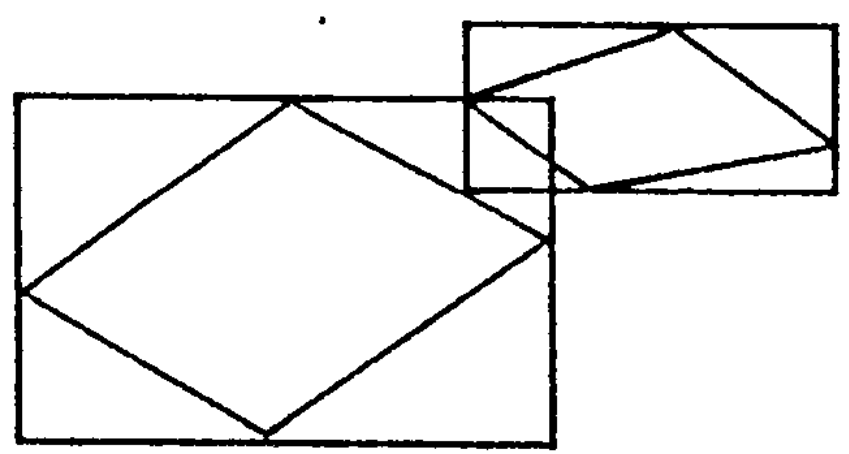

Sl. 8 - Upoređivanje zaklonjenosti poligona

\section{Preslikavanje ravni letelice $u$ ravan slike}

Termovizijske kamere sa sumiranjem ravni slike imaju prijemnu optiku fokusne dužine $\mathrm{F}$ koja preslikava ravan objekta u ravan slike [2], što je šematski prikazano na slici 9.

$\mathrm{Na}$ osnovu geometrije sa slike 9 važi relacija [1]:

$A_{2}=A_{1}\left(\frac{F}{R}\right)^{2}$ gde je:

$A_{1}$ - površina ravni objekta,

$\mathrm{A}_{2}$ - površina ravni slike,

$\mathrm{F}$ - fokusna dužina prijemne optike,

$\mathrm{R}$ - rastojanje između ravni objekta i ravni prijemne optike.

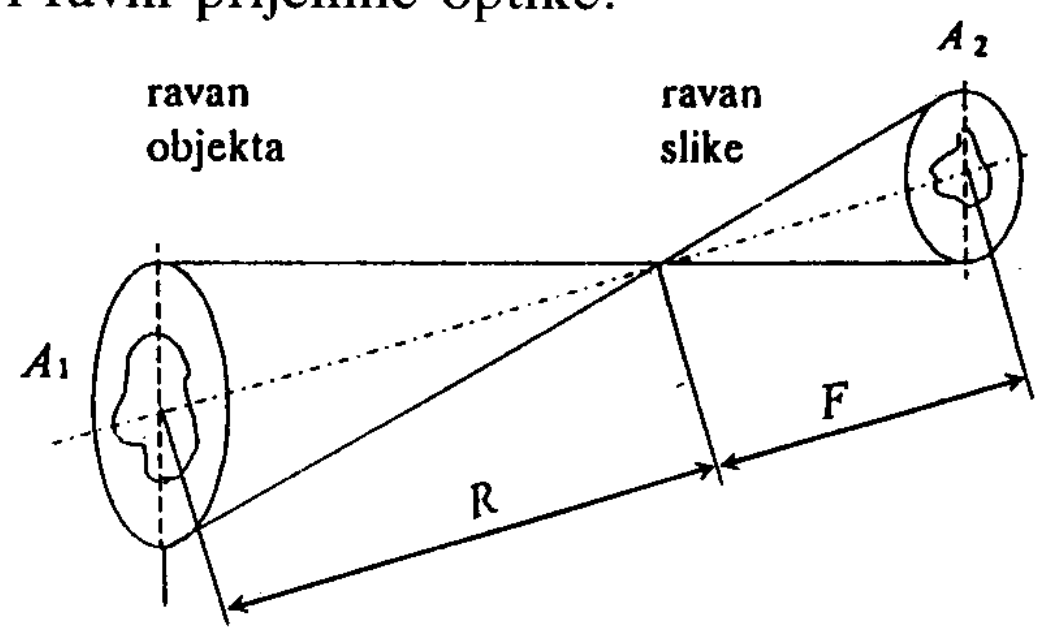

Sl. 9 - Preslikavanje ravni objekta u ravan slike

Da bi se dobila termalna slika objekta potrebno je analizirati preslikanu ravan objekta u ravni slike. Analiza ravni slike obavlja se na dva načina: dvoosnim skeniranjem ravni slike $\mathrm{i}$ matričnim detektorom sa $m \times n$ elemenata.

Svakoj elementarnoj površini letelice odgovara elementarna površina u ravni slike koja se skenira i formira signal na izlazu detektora koji odgovara jednom pikselu (tački) na termalnoj slici. Dvoosnim skeniranjem dobija se slika sa $m \times$ $n$ tačaka.

Primer analize sa dvoosnim skeniranjem ravni slike prikazan je šematski na slici 10 [10].

Primer analize ravni slike, korišćenjem matričnog detektora, prikazan je na slici 11 [10].

Svakoj elementarnoj površini u ravni slike odgovara jedan elemenat detektora koji generiše napon proporcionalan nivou određene tačke na termalnoj slici. Drugim rečima, postoji $m$ tačaka (piksela) na jednoj liniji, a $n$ je broj linija.

Simulacija na računaru kojom se dobija termovizijska slika razlikuje se od 

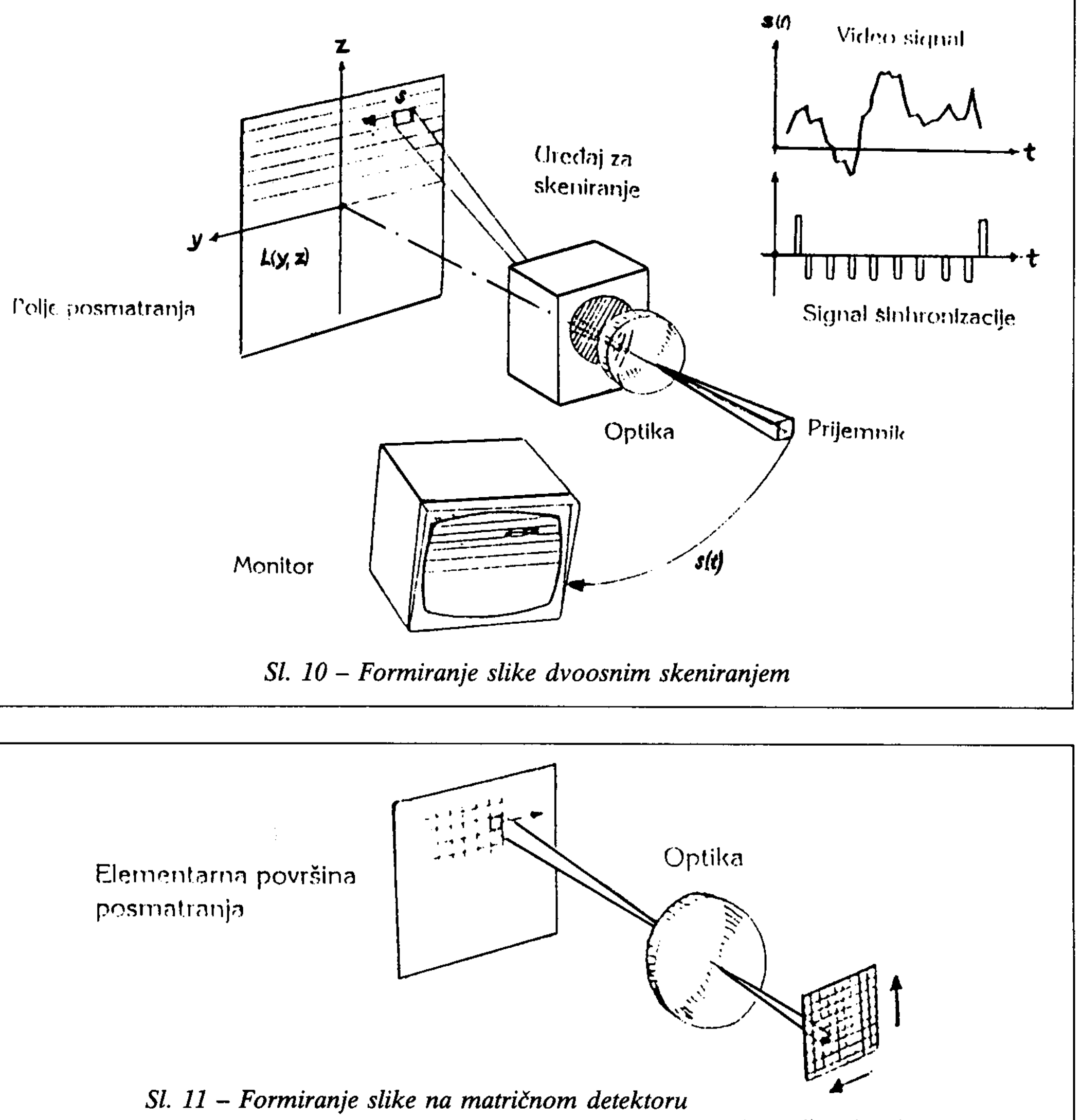

Matričnl detektor

simulacije u kojoj se ne traži odziv pojedinačnog detektora, po tome što se ne obavlja sumiranje doprinosa pojedinih elementarnih površina. Za svaku elementarnu površinu izračunava se iradijansa na mestu kamere prema relaciji (1), množi se spektralnim odzivom detektora $\mathrm{i}$ integrali $\mathrm{u}$ opsegu talasnih dužina $u$ kojima je kamera osetljiva.

\section{Termalna slika letelice dobijena matematičkim modelom}

Unošenje mreže poligona na letelici obavlja se tako da se svakom elementu površine upisuje određena temperatura. Tada se osnovna konstrukciona mreža transformiše u originalne termalne slike letelice. Radi stvaranja utiska različitih 


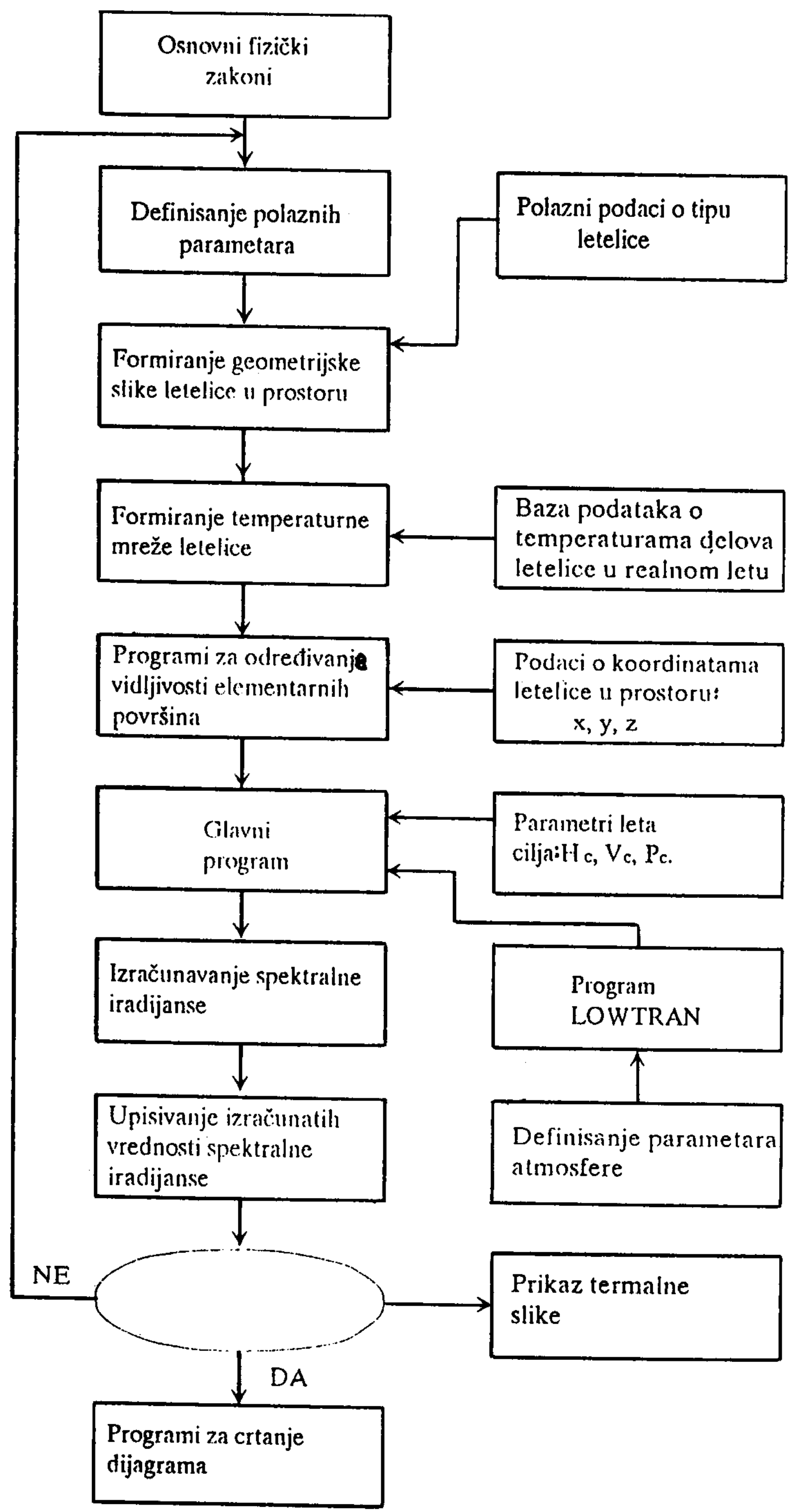

Sl. 12 - Dijagram toka proračuna za realizaciju matematickog modela 
㐫造

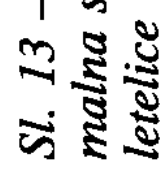
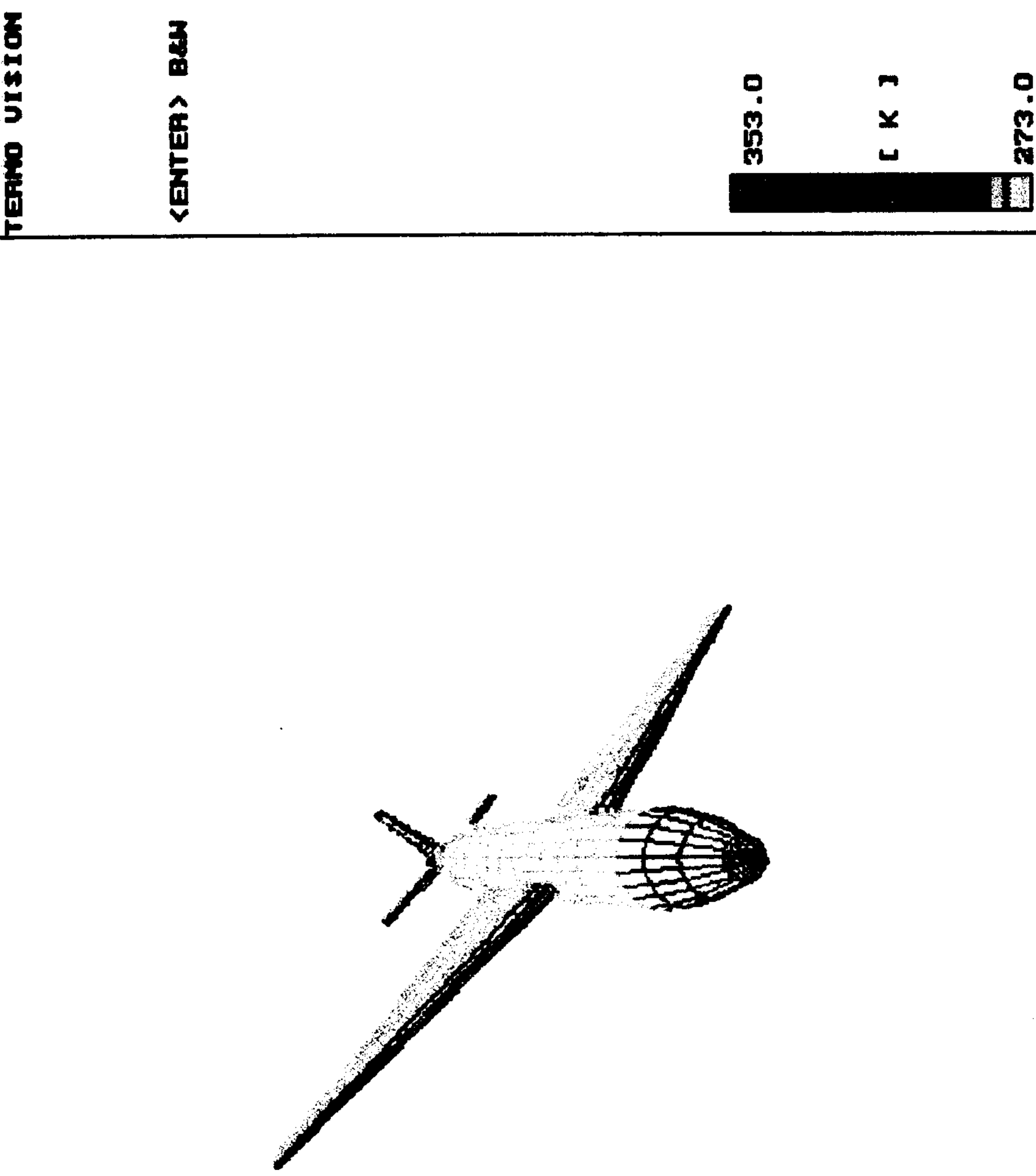
temperatura primenjena je tehnika pridodavanja određenih boja pojedinim temperaturama. Dobijene slike slične su termalnim slikama koje registruju mozaičke kamere, s tom razlikom što treba izvršiti skeniranje spotom određenih karakteristika. U okviru spota vrši se integracija doprinosa pojedinih elemenata preko sumiranja proizvoda radijanse elemenata (usred njene vrednosti za element) i elementarnog prostornog ugla pod kojim se vide elementi:

$$
\Delta \mathbf{H}_{\lambda \text { spot }}=\sum_{\text {elementi }} \mathrm{L}_{\lambda \mathrm{i}} \frac{\Delta \mathrm{A}_{\mathrm{i}} \cos \theta_{\mathrm{i}}}{\mathrm{R}^{2}}
$$

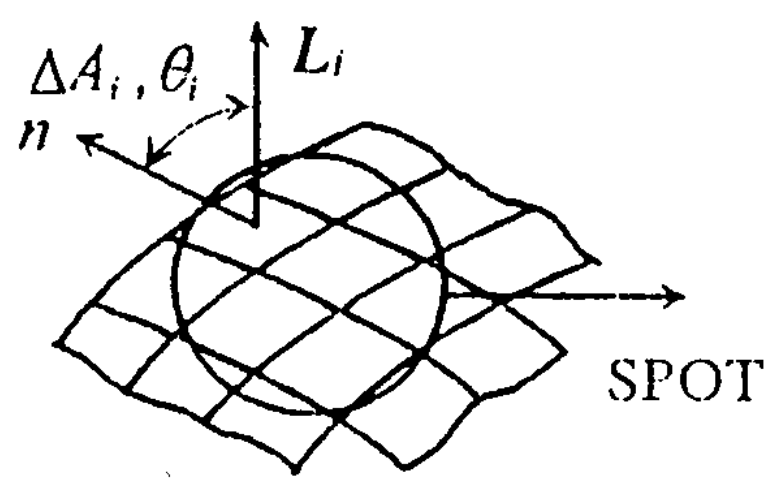

Dobijeni rezultat daje spektralnu iradijansu na odgovarajućem elementu detektora koji je pretvara u električni signal [2]. Pri tome se obavlja integracija spektralne iradijanse $\mathrm{u}$ određenom opsegu talasnih dužina. Za dobijanje slike u realnim uslovima potrebno je da se, pri integraciji iradijanse, na detektoru u obzir uzme i uticaj atmosfere koji ima efekat filtracije.

Dijagram toka realizacije matematičkog modela za formiranje termalnog odraza letelice, prikazan je na slici 12 . U računarskom modelu postoje razrađeni dijagrami i datoteke za više od 150 položaja letelica [1].

Mogućnosti programa (letelica-mreža) za ubeležavanje mreže poligona na letelici ilustrovane su primerom na slici 13.

\section{Zaključak}

Modelovanje termalnog odraza letelica izuzetno je značajno jer ukazuje na važne parametre za detekciju i identifikaciju ciljeva u vazdušnom prostoru. Ovaj model sličan je modelu opisanom u literaturi [3] koji je potpuno zatvoren, i nije dostupan.

Termalne slike letelica generisane opisanim modelom dobro se slažu sa rezultatima dobijenim eksperimentima.

Model termalnog odraza letelice potpuno je otvoren i može se poboljšavati unošenjem pozadine (neba) kao i zračenja izduvnih gasova letelice.

\section{Literatura:}

[1] Bursac, S.: Istraživanje termalnog odraza letelica, doktorska disertacija, Beograd, 1995. godina.

[2] Gaussorgues, G.: La thermographie infrarouge, prevod sa francuskog na ruski, Moskva 1988.

[3] Onear Corporation „Pc NirATAM“ BROOKLIN, SAD 1992. godina. 